\title{
Peripartum cardiomyopathy-An unsolved mystery to an anesthesiologist
}

\author{
Rashmi HD, Prajwal Patel HS, Shivaramu BT \\ Department of Anaesthesiology, Adichunchanagiri Institute of Medical Sciences, Mandya District, Karnataka, India. \\ Correspondence to: Rashmi HD, E-mail: rashpravi@gmail.com \\ Received September 30, 2014. Accepted October 9, 2014
}

\section{Abstract}

Cardiac diseases in pregnancy pose a multitude of challenges to both anesthesiologists and obstetricians. Peripartum cardiomyopathy is one of the rare causes of dilated cardiomyopathy in parturients with a great diagnostic difficulty. High degree of suspicion along with good clinical experience is needed for its diagnosis. Unfortunately, mortality from this ranges from $35 \%$ to $50 \%$. We report a case of 21 -year-old female parturient presenting at 37 weeks of gestation for emergency cesarean delivery with undiagnosed peripartum cardiomyopathy. She developed cardiac arrest soon after giving spinal anesthesia. She was successfully resuscitated and shifted to ICU for further management. Bedside echocardiography was conducted, which showed dilated cardiomyopathy with an ejection fraction of $32 \%$.

KEY WORDS: Undiagnosed peripartum cardiomyopathy, emergency cesarean delivery, cardiac arrest

\section{Introduction}

In 1971, Demakis and Rahimtoola ${ }^{[1]}$ first defined peripartum cardiomyopathy as idiopathic heart failure (HF) occurring in the absence of any determinable heart disease in the last month of pregnancy or during the first 5 months postpartum.

Current diagnostic criteria for peripartum cardiomyopathy include the following ${ }^{[1,2]}$ :

1. Development of HF in last month of pregnancy or 5 months postpartum

2. Absence of preexisting heart disease

3. Indeterminant cause

4. Echocardiographic findings (a, together with b or c; or all of these):

a. Left ventricular end-diastolic dimension $>2.7 \mathrm{~cm} / \mathrm{m}^{2}$

b. M-mode fractional shortening $<30 \%$

c. Left ventricular ejection fraction $($ LVEF) $<0.45$

\section{Case report}

A female parturient aged 21 years, second gravida, presented to us at 37 weeks of gestation. She was posted

\begin{tabular}{|l|l|}
\hline \multicolumn{2}{|c|}{ Access this article online } \\
\hline Website: http://www.jmsph.com & Quick Response Code: \\
\hline DOl: $10.5455 /$ /jmsph.2015.3009201431
\end{tabular}

for emergency cesarean delivery. Preanesthetic evaluation was conducted in detail. Clinical history, examination, and investigations were within normal limits. She did not complain of breathlessness or increased fatigability at any time during her present pregnancy. She was not on any medications except for iron and calcium tablets. She underwent cesarean delivery 3 years back for cephalopelvic disproportion under subarachnoid block without any perioperative complications. Now she presented with leaking per vagina along with labor pains. Thus, she was posted for emergency cesarean delivery. On examination, her vital parameters were found to be normal. Systemic examination did not reveal any significant findings. Her routine laboratory investigations were within normal limits. A written informed consent was taken from the patient.

Anesthetic plan for this patient was subarachnoid block. On arrival to operation room, an 18-G IV cannula was placed on the dorsum of the left hand and $500 \mathrm{~mL}$ Ringer lactate infusion was started. Monitors were connected and baseline values of pulse rate, blood pressure, and saturation were noted. Preoperative ECG was within normal limits. Patient was made to lie down in the right lateral position and subarachnoid block was instituted in the L3-L4 interspace with $26-\mathrm{G}$ spinal needle using $1.8 \mathrm{~mL}$ bupivacaine $0.5 \%$ (heavy) without any adjuvants. She was then turned to supine position immediately. Wedge was given under right hip to minimize aortocaval compression.

Immediately after turning to supine position, patient complained of breathlessness and difficulty in breathing. Her saturation began to fall and dropped down to $80 \%$. Her blood pressure dropped down $80 / 40 \mathrm{~mm} \mathrm{Hg}$. Radial pulse was not felt. Within no time patient went in for cardiac arrest. Immediately, injection adrenaline (1 mg; 1:1000) and injection 
atropine $(0.6 \mathrm{mg})$ were given intravenously (IV). She was intubated with cuffed endotracheal tube of size 7.5. Soon after, radial pulse was felt. Blood pressure shooted to $160 / 110 \mathrm{~mm} \mathrm{Hg}$. Obstetrician was asked to extract the baby as soon as possible. A live term female baby with good Apgar score was extracted. Uterus contracted well. Meanwhile, patient developed pulmonary edema. Pink frothy secretions started coming out of endotracheal tube. Pulse and blood pressure were maintained. Injection lasix (40 mg) was given IV. Second dose repeated after $20 \mathrm{~min}$. But the patient's condition did not improve. The patient was shifted to ICU for further management. She was mechanically ventilated on assist control mode along with peep after paralyzing with injection vecuronium (4 mg) IV. Propped up position was given. Injection fentanyl $(0.5 \mu \mathrm{g} / \mathrm{kg} / \mathrm{h})$ infusion was given in the ICU. A cardiology consultation was ordered. Bedside echocardiography was conducted, which showed global hypokinesia, left ventricular dysfunction with ejection fraction of $32 \%$, and cardiomegaly. It was diagnosed as peripartum dilated cardiomyopathy.

The patient was treated for HF with digoxin, diuretics, vasodilators, and bromocriptine as per the orders of cardiologist. The patient's condition improved over a period of 10 days. She was successfully extubated on 11th day and shifted to ward. She was discharged on 15th postoperative day with an advice to continue the treatment. She was told to carry the discharge and treatment card to wherever she goes for the treatment of any other diseases.

\section{Discussion}

Peripartum cardiomyopathy is one of the rare causes of dilated cardiomyopathy presenting in the last trimester of pregnancy or within first 6 months after delivery in the absence of any preexisting cardiovascular disease. It presents with the symptoms of HF. Thus, HF therapy is advocated for this condition. Treatment goals include preload and after load reduction and increasing the contractility of the heart. Diuretics and nitroglycerine are used for preload reduction, digoxin as inotropic agent, and heparin prophylaxis for maintaining anticoagulation and to avoid the risk of thromboembolism. The prognosis is best when peripartum cardiomyopathy is diagnosed and treated early. Fortunately, despite a high risk of recurrence in subsequent pregnancies, many patients with peripartum cardiomyopathy recover within 3-6 months of disease onset. ${ }^{[3]}$

Newer drugs such as bromocriptine ${ }^{[4]}$ and levosimendan ${ }^{[5]}$ have been tried in the treatment of this condition but with limited success. Levosimendan reduces pulmonary capillary wedge pressure and improves cardiac output of patients with peripartum cardiomyopathy.

Very few case reports are available about the anesthetic techniques used in case of peripartum cardiomyopathy. Both regional anesthesia ${ }^{[6-10]}$ and general anesthesia ${ }^{[11]}$ have been used with limited success for patients previously diagnosed with peripartum cardiomyopathy.
Lata et al. ${ }^{[6]}$ reported a case of previously diagnosed peripartum cardiomyopathy presenting for emergency cesarean delivery. She was already on drugs for the same. At the time of presentation, she had increasing fatigability and severe dyspnea on mild physical activity. 2D echocardiography showed left ventricular dysfunction with LVEF $<25 \%$. She was stabilized by giving lasix, digoxin, and diuretics. Lumbar epidural anesthesia was given for the patient with a combination of local anesthetic and fentanyl in titrated doses. The patient was successfully managed with no intraoperative and postoperative adverse events.

Tiwari et al. ${ }^{[7]}$ reported a case series of five patients with peripartum cardiomyopathy who were successfully managed with novel approach of epidural volume extension technique.

Kumari et al. ${ }^{[9]}$ have successfully used combined spinal and epidural technique for managing a patient of peripartum cardiomyopathy.

Soni et al. ${ }^{[11]}$ have used general anesthesia successfully for patients with peripartum cardiomyopathy.

In our case, patient had cardiac arrest soon after giving spinal anesthesia because it precipitated sudden and rapid reduction of systemic vascular resistance and thereby preload. Similar case was reported by Bajwa et al. ${ }^{[12]}$, wherein patient had cardiac arrest soon after starting of oxytocin infusion after extracting the baby.

Various such case reports ${ }^{[13,14]}$ of cardiac arrest at induction of general anesthesia in parturients posted for emergency cesarean delivery with undiagnosed peripartum cardiomyopathy are available.

\section{Conclusion}

Diagnostic difficulty is of primary concern in this condition for us as anesthesiologists while evaluating such patients in case of emergency situations. High degree of suspicion is needed for the diagnosis of this condition and it is a diagnosis of exclusion. Most of the time, slight breathlessness and fatigability are confused with the labor pains and there will be no cardinal signs in cardiovascular system examination for the diagnosis of this condition.

Still the diagnosis of peripartum cardiomyopathy remains a mystery for anesthesiologists. If we are encountered with this type of situation, HF therapy should be instituted as soon as possible for better outcome. Definitive tests are yet to be discovered for the diagnosis of this condition.

\section{References}

1. Demakis JG, Rahimtoola SH. Peripartum cardiomyopathy. Circulation 1971;44(5):964-8.

2. Manolio TA, Baughman KL, Rodeheffer R, Pearson TA, Bristow JD, Michels VV, et al. Prevalence and etiology of idiopathic dilated cardiomyopathy (summary of a National Heart, Lung, and Blood Institute workshop). Am J Cardiol 1992;69(17):1458-66. 
3. Bhattacharyya A, Basra SS, Sen P, Kar B. Peripartum cardiomyopathy-a review. Tex Heart Inst J 2012;39(1):8-16.

4. Chopra S, Verghese PP, Jacob JJ. Bromocriptine as a new therapeutic agent for peripartum cardiomyopathy Indian $\mathrm{J}$ Endocrinol Metab 2012;16(Suppl 1) S60-2.

5. Benlolo S, Lefoll C, Katchatouryan V, Payen D, Mebazaa A. Successful use of levosimendan in a patient with peripartum cardiomyopathy. Anesth Analg 2004;98:822-4.

6. Lata S, Satya Prakash MVS, Balachander H. Emergency cesarean section in Peripartum Cardiomyopathy. Anesth Essays Res 2012;6(1):91-3.

7. Tiwari AK, Agrawal J, Tayal S, Chadha M, Singla A, Valson G, et al. Anesthetic management of peripartum cardiomyopathy using "epidural volume extension" technique: a case series. Ann Cardiac Anaesth 2012;15:1.

9. Kumari I, Kumar S, Gupta S. Sequential combined spinal epidural anaesthesia for caesarean section in peripartum cardiomyopathy. Indian J Anaesth 2007:51(2):137-9.

10. Gupta K, Gupta SP, Jose S, Balchander H. Low dose spinal anesthesia for peripartum cardiomyopathy. J Anaesthesiol Clin Pharmacol 2011;27(4):567-8.
11. Soni B, Gautam PL, Grewal A, Kaur H. Anaesthetic management of two cases of peripartum cardiomyopathy. J Obstet Anaesth Critical Care 2011;1(1):41-5.

12. Bajwa SK, Bajwa SJS, Sood A. Cardiac arrest in a case of undiagnosed dilated cardiomyopathy patient presenting for emergency cesarean section. Anesth Essays Res 2010;4(2): 115-8.

13. McIndoe AK, Hammond EJ, Babington PC. Peripartum cardiomyopathy presenting as a cardiac arrest at induction of anaesthesia for emergency caesarean section. $\mathrm{Br} \mathrm{J}$ Anaesth 1995;75(1):97-101.

14. Wake K, Takanishi T, Kitajima T, Hayashi K, Takahashi H, Sakio $\mathrm{H}$. Cardiac arrest during emergency caesarean section due to Peripartum cardiomyopathy. Masui 2003;52(10):1089-91.

How to cite this article: Rashmi HD, Patel PHS, Shivaramu BT. Peripartum cardiomyopathy-An unsolved mystery to an anesthesiologist. Int J Med Sci Public Health 2015;4:304-306

Source of Support: Nil, Conflict of Interest: None declared. 